\title{
Utilization of the Genomewide Wheat 55K SNP Array for Genetic Analysis of Stripe Rust Resistance in Common Wheat Line $\mathbf{P 9 9 3 6}$
}

\author{
Shuo Huang, ${ }^{1}$ Jianhui Wu, ${ }^{1}$ Xiaoting Wang, ${ }^{1}$ Jingmei Mu, ${ }^{1}$ Zhi Xu, ${ }^{2}$ Qingdong Zeng, ${ }^{1}$ Shengjie Liu, ${ }^{1}$ Qilin Wang, ${ }^{1}$ \\ Zhensheng Kang, ${ }^{1, \dagger}$ and Dejun Han ${ }^{1, \dagger}$ \\ ${ }^{1}$ State Key Laboratory of Crop Stress Biology for Arid Areas, Northwest A\&F University, Yangling, Shaanxi 712100, P. R. China; and \\ ${ }^{2}$ Department of Plant Disease, Institute of Plant Protection, Sichuan Academy of Agricultural Sciences, Jingjusi Road 20, Jinjiang District, \\ Chengdu, Sichuan610066, P.R. China
}

Accepted for publication 11 January 2019.

\begin{abstract}
Breeding for resistance to stripe rust (caused by Puccinia striiformis f. tritici) is essential for reducing losses in yield and quality in wheat. To identify genes for use in breeding, a biparental population of 186 recombinant inbred lines (RILs) from a cross of the Chinese landrace Mingxian 169 and CIMMYT-derived line P9936 was evaluated in field nurseries either artificially or naturally inoculated in two crop seasons. Each of the RILs and parents was genotyped with the wheat $55 \mathrm{~K}$ singlenucleotide polymorphism (SNP) 'Breeders' array and a genetic linkage map with 8,225 polymorphic SNP markers spanning 3,593.37 centimorgans was constructed. Two major quantitative trait loci (QTL) and two minor QTL were identified. The major QTL QYr.nwafu-3BS.2 and QYr.nwafu-7BL on chromosomes arms 3BS and 7BL were detected in all field locations and
\end{abstract}

ABSTRACT explained an average 20.4 and $38.9 \%$ of phenotypic variation stripe rust severity, respectively. QYr.nwafu-3BS.2 likely corresponds to the locus Yr30/Sr2 and QYr.nwafu-7BL may be a resistance allele identified previously in CIMMYT germplasm. The other minor QTL had limited individual effects but increased resistance when in combinations with other QTL. Markers linked to QYr.nwafu-7BL were converted to kompetitive allele-specific polymerase chain reaction markers and validated in a panel of wheat accessions. Wheat accessions carrying the same haplotype as P9936 at the identified SNP loci had lower average stripe rust severity than the average severity of all other haplotypes.

Keywords: adult-plant resistance, yellow rust.
Stripe rust, or yellow rust, caused by Puccinia striiformis f. tritici Erikss., occurs on wheat (Triticum aestivum L.) worldwide, and causes significant economic losses by increasing the cost of disease management and reduced grain yield (Beddow et al. 2015; Hovmøller et al. 2010). As one of the most destructive diseases, it occurs periodically in almost all winter wheat-growing regions in China (Chen et al. 2014; Li and Zeng 2002). Chemicals can control stripe rust; however, the application of chemicals can substantially increase the cost of wheat production and may pollute the environment. Planting resistant wheat varieties is considered a top priority to control this disease (McIntosh et al. 1995; Wiesner-Hanks and Nelson 2016).

There are two general categories of resistance to stripe rust: race specific and race nonspecific. Race-specific resistance is generally effective at all growth stages and is often described as all-stage or seedling resistance, whereas race-nonspecific resistance tends to develop at postseedling growth stages (adult plant resistance [APR] or high-temperature adult plant resistance) and is more likely to be quantitative in effect (Chen 2013). The advantage of the latter type is that it is more likely to be durable (Johnson 1981; McDonald and

†Corresponding authors: D. J. Han; E-mail: handj@nwsuaf.edu.cn; and Z. S. Kang; E-mail: kangzs@nwsuaf.edu.cn

Funding: This study was financially supported by the Genetically Modified Organisms Breeding Major Project (2016ZX08002001), the National Key Research and Development Program of China (grant number 2016YFE0108600), the Earmarked Fund for Modern Agro-industry Technology Research System (number CARS-3-1-11), and the National Science Foundation for Young Scientists of China (grant 31701421).

$\mathrm{S}$. Huang and $\mathrm{J}$. Wu made equal contribution to this study.

*The $\boldsymbol{e}$-Xtra logo stands for "electronic extra" and indicates that one supplementary figure and four supplementary tables are published online.

The author(s) declare no conflict of interest.

(c) 2019 The American Phytopathological Society
Linde 2002); Race-nonspecific resistance may be controlled by several genes with either major or minor effects (Chen 2013). Many wheat cultivars are reported to have durable resistance or APR (Boyd 2005; Ellis et al. 2014; McIntosh 1992). More than 300 genes or quantitative trait loci (QTL) for resistance to stripe rust have been mapped on all 21 wheat chromosomes and most are listed in the Wheat Catalogue of Gene Symbols or summarized in other publications (Bulli et al. 2016; Maccaferri et al. 2015; McIntosh et al. 2017; Rosewarne et al. 2013). However, most all-stage resistance genes are no longer effective against prevalent races in China and only several APR genes, such as $Y r 18, Y r 29, Y r 30, Y r 36$, Yr39, $Y r 46, Y r 52, Y r 54, Y r 59, Y r 62, Y r 78$, and $Y r 79$, are reported to reduce stripe rust among wheat varieties (Feng et al. 2018, Wu et al. 2016; Wu et al. 2018b; Zeng et al. 2015; Zhou et al. 2015). Unfortunately, not all of the effective genes or QTL have molecular markers that could be useful for marker-assisted selection (MAS). Therefore, it is necessary to identify more resistance genes or QTL with user-friendly markers.

QTL analysis using molecular markers is an efficient way to dissect complex traits. However, a lack of high-resolution polymorphic markers was the biggest constraint in QTL mapping of hexaploid wheat in the past. As a consequence, target QTL are often located in large chromosomal regions and MAS is limited to relatively low numbers of well-validated markers (Wang et al. 2015). Recently, next-generation sequencing and high-throughput genotyping technologies have revolutionized the QTL analysis of complex traits and enabled rapid marker development and map construction (Wang et al. 2018). Several high-density, singlenucleotide polymorphism (SNP) chips and platforms, such as Affymetrix Gene Chip, Illumina Bead Array, and kompetitive allele-specific polymerase chain reaction (KASP) (https://www. biosearchtech.com/) are now available for wheat genetic studies (Rasheed et al. 2016, 2017; Wu et al. 2017b, 2018c). SNP chips containing different numbers of markers, including $9 \mathrm{~K}, 35 \mathrm{~K}, 90 \mathrm{~K}$, and $660 \mathrm{~K}$, are commercially available (Allen et al. 2017; Cavanagh 
et al. 2013; Cui et al. 2017; Wang et al. 2014). The newly designed Axiom wheat 55K SNP array is more appropriate for wheat genetic research because all 53,063 SNP probes were carefully selected from the wheat $660 \mathrm{~K}$ SNP array for polymorphisms across a set of global wheat varieties (Jia and Zhao 2016). Based on the advantages of lower costs, less "ascertainment bias", and more scorable marker sites, this newly developed SNP array has been used in QTL studies (Liu et al. 2018; Ren et al. 2018; Wu et al. 2018a).

One of the objectives of the International Maize and Wheat Improvement Center (CIMMYT) is to strengthen the genetic diversity of resistance in its wheat germplasm (Guzmán et al. 2017). Many CIMMYT wheat lines have been introduced to China. In an earlier study, more than 1,000 common wheat accessions, including many from CIMMYT, were assessed for stripe rust response in both greenhouse and field environments (Han et al. 2012). Among these, line P9936 with pedigree Bluebird/Gallo $\times$ Cajeme//F35.70 $\times$ Kalyansona/Bluebird (CIMMYT 1983) consistently displayed high resistance against stripe rust at the adult-plant stage (Han et al. 2012). However, the genetic basis of its resistance was unknown. The goals of this study were to (i) map the stripe rust resistance of P9936 using a high-density SNP map developed for a Mingxian $169 \times$ P9936 recombinant inbred line (RIL) population, (ii) identify QTL for stripe rust APR across multiple environments using SNPbased genomewide scanning, and (iii) develop user-friendly markers for use in breeding programs.

\section{MATERIALS AND METHODS}

Wheat materials. The biparental population comprised 186 $\mathrm{F}_{6}$-derived $\mathrm{F}_{7}$ RILs from the cross Mingxian $169 \times \mathrm{P} 9936$. Mingxian 169 (MX169) is a stripe-rust-susceptible Chinese winter wheat landrace. The susceptible controls used in this study throughout the experiment were MX169, Avocet S (AvS), and Xiaoyan 22 (XY22). A diverse panel of 361 common wheat varieties was assessed for SNP-based haplotypes. The goal was to identify useful SNP markers linked to stripe rust resistance QTL for

TABLE 1. Summary of adult responses to stripe rust in the Mingxian 169 $($ MX169) $\times$ P9936 recombinant inbred line population in 2017 and 2018 at Yangling (YL), Jiangyou (JY), Tianshui (TS), and best linear unbiased prediction (BLUP) ${ }^{\mathrm{a}}$

\begin{tabular}{|c|c|c|c|c|c|c|c|}
\hline \multirow[b]{2}{*}{ Environment } & \multicolumn{4}{|c|}{ Disease severity (\%) } & \multirow[b]{2}{*}{$\sigma g^{2}$} & \multirow[b]{2}{*}{$\mathrm{SD}$} & \multirow[b]{2}{*}{$h_{b}^{2}$} \\
\hline & MX169 & P9936 & Mean & Range & & & \\
\hline 2017YL & 100.0 & 15.0 & 49.0 & $3-100$ & 891.8 & 29.9 & 0.96 \\
\hline 2018YL & 100.0 & 10.0 & 40.6 & $1-95$ & 1036.9 & 32.2 & - \\
\hline 2017JY & 95.0 & 7.5 & 27.0 & $0.5-80$ & 672.1 & 25.9 & 0.94 \\
\hline 2018JY & 97.5 & 10.0 & 31.8 & $0-90$ & 613.9 & 24.8 & 0.92 \\
\hline 2017TS & 95.0 & 10.0 & 42.0 & $5-97$ & 838.8 & 29.0 & 0.89 \\
\hline 2018TS & 95.0 & 12.5 & 43.1 & $5-97.5$ & 819.0 & 28.6 & 0.73 \\
\hline BLUP & 100.0 & 10.0 & 38.9 & $7.7-86$ & 478.1 & 21.9 & - \\
\hline
\end{tabular}

a $\mathrm{SD}=$ standard deviation and - indicates not calculated.

TABLE 2. Correlation coefficients ( $r$ ) of mean disease severities (DS) for the MX169 × P9936 recombinant inbred line population across six environments ${ }^{\mathrm{a}}$

\begin{tabular}{llccccc}
\hline Environment $^{\mathrm{b}}$ & $2017 \mathrm{YL}$ & $2017 \mathrm{JY}$ & $2017 \mathrm{TS}$ & $2018 \mathrm{YL}$ & $2018 \mathrm{JY}$ & $2018 \mathrm{TS}$ \\
\hline $2017 \mathrm{YL}$ & 1.00 & $\ldots$ & $\ldots$ & $\ldots$ & $\ldots$ & $\ldots$ \\
$2017 \mathrm{JY}$ & $0.52 * * * \mathrm{~b}$ & 1.0000 & $\ldots$ & $\ldots$ & $\ldots$ & $\ldots$ \\
$2017 \mathrm{TS}$ & $0.63 * * *$ & $0.78^{* * *}$ & 1.0000 & $\ldots$ & $\ldots$ & $\ldots$ \\
$2018 \mathrm{YL}$ & $0.53 * * *$ & $0.46^{* * *}$ & $0.50 * * *$ & 1.0000 & $\ldots$ & $\ldots$ \\
$2018 \mathrm{JY}$ & $0.63 * * *$ & $0.51 * * *$ & $0.49 * * *$ & $0.66 * * *$ & 1.0000 & $\ldots$ \\
$2018 \mathrm{TS}$ & $0.65^{* * *}$ & $0.44 * * *$ & $0.46^{* * *}$ & $0.68 * * *$ & $0.72 * * *$ & 1.0000 \\
\hline
\end{tabular}

a Asterisks (***) indicate that all $r$ values were significant at $P=0.001$.

b YL, TS, and JY = Yangling, Tianshui, and Jiangyou, respectively, during the 2016-17 and 2017-18 cropping seasons. use in MAS. The wheat accessions that made up the panel were kindly provided by the China Agriculture Research System.

Greenhouse trials. Evaluation of seedling reactions to different $P$. striiformis f. tritici races was conducted under controlled greenhouse conditions in a previous study (Han et al. 2012). In this study, for seedling tests, 10 seeds of each parent were sown in 9-by-9-by-9-cm pots and, for adult-plant tests, three plants were grown in larger pots $(20 \mathrm{~cm}$ in diameter by $15 \mathrm{~cm}$ in height). Seedlings at the two-leaf stage (14 days after planting) and adult plants at the booting stage were separately inoculated with urediniospores of $P$. striiformis f. tritici races CYR32, CYR33, and CYR34 mixed with talc at a ratio of approximately 1:20. Infection types (ITs) were recorded 18 to 21 days after inoculation using a 0-to-9 scale (Line and Qayoum 1992). Plants with ITs 0 to 6 were considered resistant and plants with ITs 7 to 9 were considered susceptible. In order to confirm and clarify ITs of the entries, all tests were repeated three times.

Field trials. Stripe rust responses were assessed at three locations over 2 years. The locations were Yangling in Shaanxi Province, Tianshui in Gansu Province, and Jiangyou in Sichuan Province and the trails were conducted during the 2016-17 and 2017-18 crop seasons (hereafter 2017 and 2018, respectively). All field plots were sown between mid-September and early November. After every 20 rows in the field, the susceptible check XY22 and parents were used to increase and check stripe rust uniformity. The susceptible lines AvS and MX169 were planted as spreader rows surrounding the fields to ensure adequate inoculum for infection. At the jointing stage (usually in late March) in the fields at Yangling, the susceptible checks were artificially inoculated with a mixture of urediniospores of prevalent races CYR32 and CYR34 suspended in liquid paraffin (1:300). The experiments at Tianshui and Jiangyou were subjected to natural infection because both locations are hotspot regions for stripe rust. A randomized complete block design with two replications was used in all experiments. Thirty seeds of each line were planted in $120-\mathrm{cm}$ rows spaced $30 \mathrm{~cm}$ apart. Parents and progenies were visually evaluated for disease severity using a modified Cobb scale (Peterson et al. 1948) when stripe rust severity levels of susceptible checks reached maximum levels of 90 to $100 \%$ at 18 to 20 days postflowering (approximately 15 to 20 May at Yangling, 10 to 15 April at Jiangyou, and 10 to 15 June at Tianshui). Disease assessment was made at least twice and, generally, the final dataset (the maximum disease severity [MDS]) was used for phenotypic and QTL analyses.

Phenotypic analysis. Analysis of variance (ANOVA) was conducted using the MDS data to determine the effects of genotypes, environments, and genotype-environment interaction. Pearson's correlation coefficient (PCC) analysis and ANOVA were conducted using the "AOV" function in QTL IciMapping software (version 4.1) with the default parameters (Meng et al. 2015). Estimation of broad-sense heritability $\left(h_{b}{ }^{2}\right)$ of resistance to stripe rust was based on the equation $h_{b}{ }^{2}=\sigma_{g}{ }^{2} /\left(\sigma_{g}{ }^{2}+\sigma_{g e}{ }^{2} / e+\sigma_{\varepsilon}{ }^{2} / r e\right)$, where $\sigma_{g}{ }^{2}$ is $\left(M S_{\mathrm{f}}-M S_{\mathrm{fe}}\right) / r e, \sigma_{g e}{ }^{2}$ is $\left(M S_{\mathrm{fe}}-M S_{\mathrm{e}}\right) / r$, and $\sigma_{\varepsilon}{ }^{2}$ is $M S_{\mathrm{e}}$; and $\sigma_{g}{ }^{2}=$ genetic variance, $\sigma_{g e}{ }^{2}=$ genotype-environment interaction variance, $\sigma_{\varepsilon}{ }^{2}=$ error variance, $M S_{\mathrm{f}}=$ mean square of genotypes, $M S_{\mathrm{fe}}=$ mean square of genotype-environment interaction, $M S_{\mathrm{e}}=$ mean square of error, $r=$ number of replications, and $e=$ number of environments.

Average phenotypic values for RILs in each environment were used for analyses. The genetic effects from six environments were evaluated using the $\mathrm{R}$ package lme4 of best linear unbiased prediction (BLUP), where lines, environments, line-environment interaction, and replicates nested in environments were all treated as random effects (Bates et al. 2015).

Genotyping of the RIL population. Fresh leaves of RILs and parents were sampled in the field at the early-jointing stage. Genomic DNA was extracted using the sodium dodecyl sulfonate method (Weining et al. 1994). The two parents and RIL population ( $N=186$ genotypes) were genotyped with the 55K iSelect SNP array. All genotyping using the SNP array was carried out by CapitalBio 
Corporation (http://www.capitalbio.com/). The polyploid version of Affymetrix Genotyping Console software was used for SNP genotype calling and allele gathering. Low-quality SNPs with $>10 \%$ missing values and major allele frequencies $>95 \%$ were removed. The polymorphic SNPs within QTL peaks were converted to KASP markers (Supplementary Table S1). The procedures used for SNP conversion to KASP markers and selective KASP assaying are described by Ramirez-Gonzalez et al. (2015) and Wu et al. (2017b).
Linkage groups construction and QTL mapping. The $\chi^{2}$ test for goodness of fit was used to test the segregation of SNP markers $(P>0.001)$. Markers significantly different from a onelocus segregation ratio were excluded. Redundant, cosegregating markers were first binned using the "BIN" function in the software QTL IciMapping V4.1 (Meng et al. 2015; Wang 2009). Then, one marker was randomly selected in case markers had the same genotype in each bin. Linkage group construction was based on the

TABLE 3. Single-nucleotide polymorphism (SNP) marker statistics for distribution and density on 21 wheat chromosomes derived from cross between MX169 and P9936

\begin{tabular}{|c|c|c|c|c|c|c|c|}
\hline Chromosome & Linkage group ${ }^{a}$ & Number of markers & Percentage of all markers & Number of bins & Length (cM) & Average markers/bin & Marker density ${ }^{\mathrm{b}}$ \\
\hline $1 \mathrm{~A}$ & G1 & 587 & 6.03 & 184 & 216.59 & 1.18 & 2.71 \\
\hline $1 \mathrm{~B}$ & $\mathrm{G} 2$ & 363 & 4.13 & 105 & 148.55 & 1.41 & 2.44 \\
\hline 1D & G3 & 54 & 2.55 & 15 & 91.77 & 6.12 & 0.59 \\
\hline $2 \mathrm{~A}$ & G4 & 403 & 4.85 & 80 & 174.22 & 2.18 & 2.31 \\
\hline $2 \mathrm{~B}$ & $\mathrm{G} 5+\mathrm{G} 6$ & 206 & 4.87 & 91 & 175.03 & 1.92 & 1.18 \\
\hline $2 \mathrm{D}$ & $\mathrm{G} 7+\mathrm{G} 8$ & 126 & 3.68 & 33 & 132.32 & 4.01 & 0.95 \\
\hline $3 \mathrm{~A}$ & G9 & 641 & 7.44 & 177 & 267.34 & 1.51 & 2.40 \\
\hline $3 B$ & G10 & 1022 & 8.10 & 197 & 291.16 & 1.48 & 3.51 \\
\hline $3 \mathrm{D}$ & $\mathrm{G} 11+\mathrm{G} 12$ & 37 & 1.55 & 12 & 55.57 & 4.63 & 0.67 \\
\hline $4 \mathrm{~A}$ & G13 & 240 & 5.23 & 101 & 187.92 & 1.86 & 1.28 \\
\hline 4BS/6AS & $\mathrm{G} 14+\mathrm{G} 15$ & 116 & 3.14 & 54 & 112.84 & 2.09 & 1.03 \\
\hline $4 \mathrm{D}$ & G16 & 34 & 2.06 & 24 & 74.17 & 3.09 & 0.46 \\
\hline $5 \mathrm{~A}$ & G17 & 855 & 9.26 & 174 & 332.61 & 1.91 & 2.57 \\
\hline $5 B$ & G18 & 618 & 6.93 & 169 & 249.15 & 1.47 & 2.48 \\
\hline $5 \mathrm{D}$ & $\mathrm{G} 19+\mathrm{G} 20$ & 72 & 1.67 & 30 & 60.16 & 2.01 & 1.20 \\
\hline 4BL/6AL & $\mathrm{G} 21+\mathrm{G} 22$ & 123 & 2.88 & 49 & 103.46 & 2.11 & 1.19 \\
\hline $6 \mathrm{~B}$ & $\mathrm{G} 23$ & 769 & 3.83 & 120 & 137.62 & 1.15 & 5.59 \\
\hline $6 \mathrm{D}$ & $\mathrm{G} 24+\mathrm{G} 25$ & 76 & 2.46 & 50 & 88.23 & 1.76 & 0.86 \\
\hline $7 \mathrm{~A}$ & $\mathrm{G} 26$ & 892 & 8.71 & 209 & 312.88 & 1.50 & 2.85 \\
\hline $7 \mathrm{~B}$ & $\mathrm{G} 27$ & 958 & 6.95 & 179 & 249.88 & 1.40 & 3.83 \\
\hline 7D & $\mathrm{G} 28$ & 33 & 3.67 & 22 & 131.9 & 6.00 & 0.25 \\
\hline A genome & 8 & 3741 & 44.39 & 974 & $1,595.02$ & 1.64 & 2.35 \\
\hline$B$ genome & 9 & 4052 & 37.97 & 915 & $1,364.23$ & 1.49 & 2.97 \\
\hline D genome & 11 & 432 & 17.65 & 186 & 634.12 & 3.41 & 0.68 \\
\hline Total & 28 & 8225 & $\ldots$ & 2,075 & $3,593.37$ & 1.73 & 2.29 \\
\hline
\end{tabular}

a Pairs of numbers indicate two separated linkage groups.

b Marker density (locus/centimorgan [cM]) was calculated by dividing the added number of unique loci by their added genetic length.

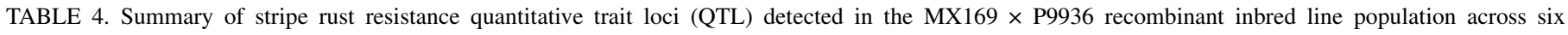
environments using inclusive composite interval mapping (ICIM) and composite interval mapping (CIM)

\begin{tabular}{|c|c|c|c|c|c|c|c|}
\hline QTL, environment ${ }^{\mathrm{a}}$ & \multicolumn{2}{|c|}{ Marker interval } & ICIM LOD $^{\mathrm{b}}$ & $\mathrm{PVE}^{\mathrm{c}}$ & Closest marker & CIM LOD & $R^{2 \mathrm{~d}}$ \\
\hline \multicolumn{8}{|l|}{ QYr.nwafu-3DS } \\
\hline 2017JY-DS & $A X-109280169$ & $A X-110686188$ & 2.6 & 3.3 & $A X-110686188$ & 2.5 & 0.03 \\
\hline 2017TS-DS & $A X-109280169$ & $A X-110686188$ & 4.3 & 6.1 & $A X-109280169$ & 3.4 & 0.05 \\
\hline 2018TS-DS & $A X-109280169$ & $A X-110686188$ & 5.1 & 7.5 & $A X-109280169$ & 4.0 & 0.08 \\
\hline DS-BLUP & $A X-109280169$ & $A X-110686188$ & 3.2 & 4.2 & $A X-109280169$ & 3.2 & 0.04 \\
\hline \multicolumn{8}{|l|}{ QYr.nwafu-3BL } \\
\hline 2017JY-DS & $A X-109329844$ & $A X-111030999$ & 2.6 & 6.2 & $A X-111030999$ & 3.5 & 0.06 \\
\hline 2018JY-DS & $A X-109329844$ & $A X-111030999$ & 2.4 & 5.5 & $A X-111030999$ & 4.1 & 0.08 \\
\hline DS-BLUP & $A X-109329844$ & $A X-111030999$ & 2.9 & 6.0 & $A X-111030999$ & 3.7 & 0.06 \\
\hline \multicolumn{8}{|l|}{ QYr.nwafu-3BS } \\
\hline 2017YL-DS & $A X-111487728$ & $A X-109919508$ & 14.2 & 27.5 & $A X-111487728$ & 16.8 & 0.23 \\
\hline 2018YL-DS & $A X-109919508$ & $A X-111107404$ & 7.4 & 17.1 & $A X-109919508$ & 8.6 & 0.10 \\
\hline 2017JY-DS & $A X-111487728$ & $A X-109919508$ & 3.9 & 9.2 & $A X-109919508$ & 3.2 & 0.04 \\
\hline 2018JY-DS & $A X-111487728$ & $A X-109919508$ & 4.5 & 9.6 & $A X-111487728$ & 4.3 & 0.06 \\
\hline 2017TS-DS & $A X-111487728$ & $A X-109919508$ & 11.1 & 24.3 & $A X-111487728$ & 13.7 & 0.20 \\
\hline 2018TS-DS & $A X-108849053$ & $A X-94545746$ & 2.1 & 5.5 & $A X-94545746$ & 3.2 & 0.05 \\
\hline DS-BLUP & $A X-111487728$ & $A X-109919508$ & 9.3 & 20.4 & $A X-111487728$ & 11.4 & 0.13 \\
\hline \multicolumn{8}{|l|}{ QYr.nwafu-7BL } \\
\hline 2017YL-DS & $A X-108819274$ & $A X-110470708$ & 9.2 & 20.7 & $A X-110470708$ & 9.8 & 0.22 \\
\hline 2018YL-DS & $A X-108819274$ & $A X-110470708$ & 18.2 & 35.9 & $A X-108806378$ & 16.5 & 0.31 \\
\hline 2017JY-DS & $A X-108818685$ & $A X-111703868$ & 16.5 & 33.3 & $A X-110611968$ & 19.7 & 0.36 \\
\hline 2018JY-DS & $A X-108819274$ & $A X-110470708$ & 14.2 & 30.9 & $A X-110028937$ & 15.6 & 0.29 \\
\hline 2017TS-DS & $A X-108819274$ & $A X-110470708$ & 10.7 & 25.1 & $A X-110611968$ & 13.1 & 0.27 \\
\hline 2018TS-DS & $A X-111510102$ & $A X-109395779$ & 9.7 & 21.7 & $A X-110470708$ & 10.3 & 0.22 \\
\hline DS-BLUP & $A X-108819274$ & $A X-110470708$ & 19.1 & 38.9 & $A X-110470708$ & 19.2 & 0.36 \\
\hline
\end{tabular}

a YL, TS, and JY = Yangling, Tianshui, and Jiangyou, respectively; BLUP = best linear unbiased prediction.

b LOD = logarithm of odds score.

c $\mathrm{PVE}=$ percentages of the phenotypic variance explained by individual QTL.

${ }^{\mathrm{d}} R^{2}=$ percentages of the phenotypic variance explained by individual QTL. 
filtered markers using the "MAP" function in QTL IciMapping V4.1, and MapChart V2.3 was used to draw the maps (Voorrips 2002). The identity positions of linkage groups were determined according to the wheat $660 \mathrm{~K}$ integrated maps (Cui et al. 2017).

The average values of RILs in each environment and BLUP values were used for QTL detection. Inclusive composite interval mapping (ICIM) of additive tool in IciMapping V 4.1 and composite interval mapping (CIM) in Windows QTL Cartographer V2.5 were carried out to detect QTL. When the logarithm of odds (LOD) score was greater than the calculated threshold value ( $\mathrm{LOD}=2.5$ to 4$)$, the corresponding QTL was considered significant. Because a single QTL peak has minor differences among LOD contours across different environments, QTL with either overlapping confidence intervals or sharing flanking markers using different programs were

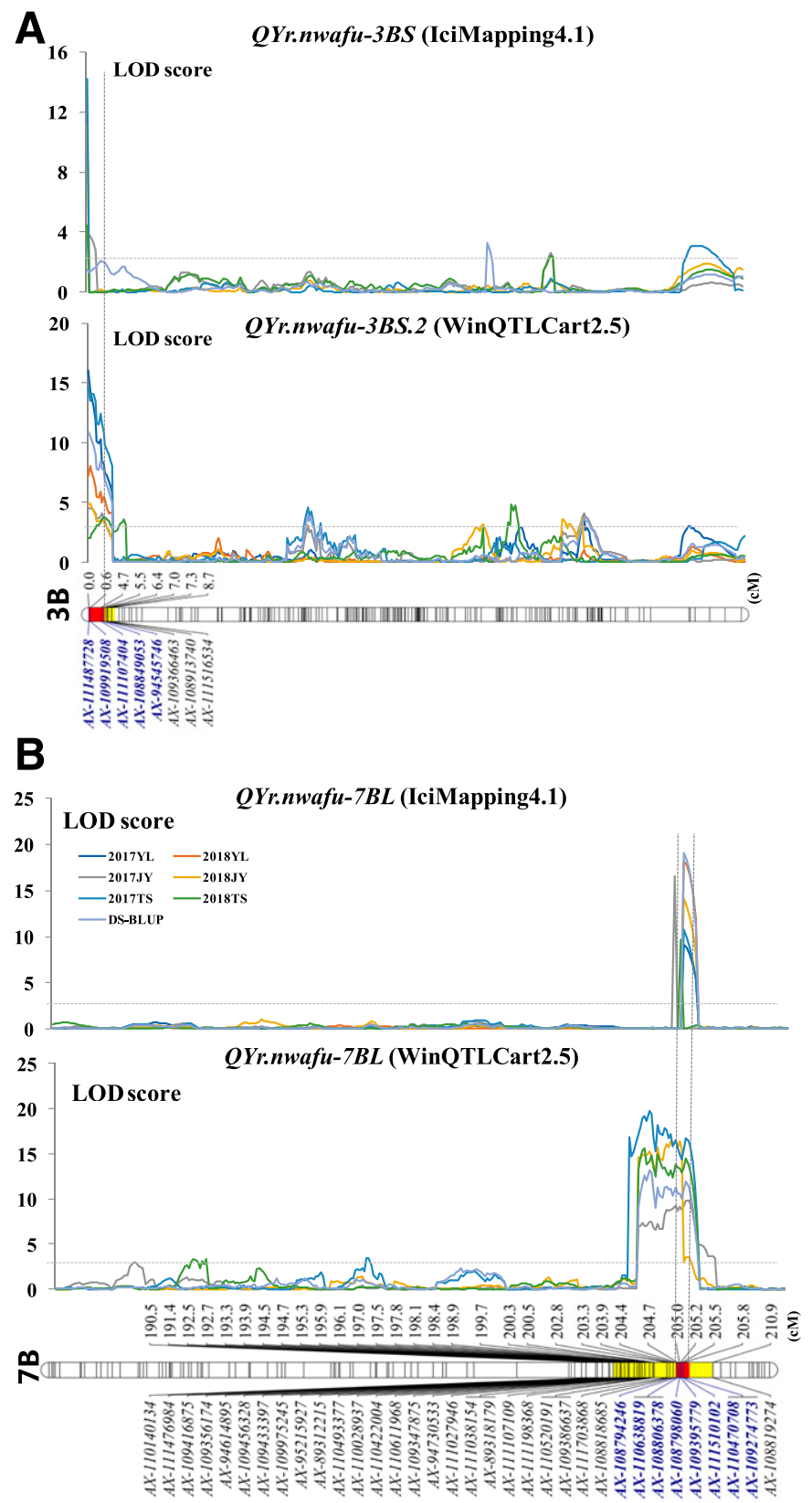

Fig. 1. Graphical display of positions of quantitative trait loci (QTL) for stripe rust resistance across all environments. Overlapping confidence intervals of QTL are based on IciMapping 4.1 (upper) and Windows QTL Cartographer 2.5 (lower). Genetic linkage maps of A, QYr.nwafu-3BS and B, QYr.nwafu$7 B L$. LOD $=$ logarithm of odds. Overlapping confidence intervals are dark gray, and markers surrounding the QTL are in bold font. considered to be identical. The proportion of phenotypic variance explained was used to estimate the effect of an individual QTL.

KASP marker validation. SNP markers closely linked to stripe rust resistance QTL were converted to KASP markers following the previously described method (Ramirez-Gonzalez et al. 2015; Wu et al. 2017b). The KASP markers were used to genotype a panel of 361 wheat lines, which were evaluated for reaction to stripe rust using the methods described by Zeng et al. (2014) and used for marker validation. Univariate ANOVA was used to analyze markertrait associations in Office Excel 2016 (Microsoft).

\section{RESULTS}

Stripe rust responses of the parents and RILs. In the seedling experiments with $P$. striiformis $\mathrm{f}$. tritici races CYR32, CYR33, and CYR34, P9936 was susceptible (IT 8 to 9); however, it was resistant (IT 1 to 2 ) in adult-plant-stage tests. The susceptible parent MX169 was susceptible (IT 8 to 9) at both seedling and adultplant growth stages. In the five field environments, stripe rust developed to adequate levels for scoring high-quality phenotypic data. MX169 was susceptible (IT 9, disease severity $[D S] \geq 90$ ) and P9936 was resistant (IT 1 to 2, DS $\leq 20$ ). Mean DS for the 186 RILs was 49, 27, and 35.0\% at Yangling, Jiangyou, and Tianshui in 2017, respectively, and 40.6, 42.0, and $38.9 \%$ at the same locations in 2018 (Table 1). The DS distributions showed continuous variation in all environments (Supplementary Fig. S1), indicating the quantitative inheritance of APR. Pearson's correlation coefficients of pairwise comparison for the six environments ranged from 0.44 to $0.78(P<0.01)$ (Table 2$). P$ values in the ANOVA of RIL scores showed significant phenotypic variation in DS among lines, environments, and line-environment interactions whereas there was no significant variation between the replications. Lines were the main source of phenotypic variation. Heritabilities were high, ranging from 0.73 to 0.96 for all data sets (Table 1). Expression of APR was uniform across all environments.

Genomewide SNP scan and linkage map. To test for the presence of resistance QTL, we generated a linkage map for the MX169 $\times$ P9936 population. The 55K SNP array was used to genotype all 186 RILs and parents. In total, 10,133 SNP loci were polymorphic between the parents, from which 1,840 were removed due to $>10 \%$ missing data or distorted segregation. The remaining 8,293 SNP fell into 2,075 bins. After removing redundant SNPs, 2,075 SNPs were used to construct a linkage map of 28 linkage groups, representing all 21 chromosomes. Fewer SNP markers were present in the D genome (186 markers) than in the A (974 markers) and B (915 markers) genomes. Only 22 markers were ungrouped. Chromosomes 2B, 2D 3D, 4B, 5D, 6A, and 6D were represented by two or more linkage groups, whereas the remaining 14 chromosomes each was represented by a single linkage group. The entire linkage map was 3,593.37 centimorgans (cM), with an average bin interval of $1.73 \mathrm{cM}$ (Table 3 ). Only linkage groups with significant stripe rust resistance QTL are presented below.

QTL analysis. Using ICIM and CIM, four QTL for stripe rust resistance were detected in chromosome arms 3BS, 3BL, 3DS, and 7BL; all were derived from P9936. QTL QYr.nwafu-3BS and $Q Y r$. $n w a f u-7 B L$ were identified in all environments and in the BLUP analysis and, therefore, were considered stable. QYr.nwafu-3BS flanked by SNP markers $A X-111487728$ and $A X-109919508$ was located in a $0.6-\mathrm{cM}$ overlapping confidence interval and explained average values of 13.0 and $20.4 \%$ of the phenotypic variation in CIM and ICIM, respectively (Table 4; Fig. 1A). The largest effect QTL, QYr.nwafu-7BL, explained an average of $38.9 \%$ (ICIM) and $36.0 \%$ (CIM) of the phenotypic variation across environments (Table 4; Fig. 1B). This QTL was mapped to a 9.04-cM region and the overlapping confidence interval was a $1.0-\mathrm{cM}$ region spanned by markers $A X-108819274$ and $A X-110470708$ (Fig. 1B). Mean DS for RILs carrying $Q Y$ r.nwafu-7BL ranged from 1 to $65 \%$, compared with 10 to $100 \%$ for RILs lacking the allele (Fig. 2A and B). Two 
QTL with small effects $(<10 \%)$ were each identified in only one location and were considered unstable or environmentally dependent. QYr.nwafu-3BL was linked to markers $A X-109329844$ and $A X-111030999$ and $Q Y$ r.nwafu-3DS was linked to markers $A X$ 109280169 and $A X-110686188$ (Table 4).

To determine interaction effects, the QTL were used to classify the RILs into different genotypic groups according to the presence of the linked markers (Supplementary Table S2). Because QYr.nwafu$7 B L$ was the largest-effect QTL, it was individually combined with the other QTL. Significant additive effects were detected. Lines with higher numbers of resistance QTL had lower average DS. Lines with all four had low DS values, ranging from 13.9 to $19.0 \%$ across all environments, similar to the resistant parent (Fig. 2C). RILs with no QTL were highly susceptible (DS $>80 \%$ ), similar to the susceptible parent. The phenotypic variance explained in the BLUP analysis accounted for 45.3 to $69.5 \%$ of the total phenotypic variation.

Location of the major QTL in chromosome 7BL. The QTL on $7 \mathrm{BL}$ was mapped to an overlapping confidence interval $1.0 \mathrm{cM}$ between SNP markers $A X-108819274$ and $A X-110470708$ based on CIM and ICIM, which corresponded to a $2.0-\mathrm{Mb}$ physical interval (Fig. 3A and B; Supplementary Table S3). Compared with the positions of expressed sequence tags in the $7 \mathrm{~B}$ deletion bin map, deletion bin 7BL5-0.86-1.00 likely contained QYr.nwafu-7BL (https://wheat.pw.usda.gov/cgi-bin/westsql/map_locus.cgi; Fig. 3C).

To deduce the position of $Q Y$ r.nwafu- $7 B L$ relative to previously mapped stripe rust resistance genes or QTL on chromosome 7BL, two integrated genetic maps were used to make comparisons (Cui et al. 2017; Maccaferri et al. 2015) (F. Cui, personal communication). Based on the QTL of flanking markers, all genes or QTL were arranged in the integrated genetic map. Most were concentrated in two intervals, 224.0 to $282.4 \mathrm{cM}$ and 328.5 to $402.3 \mathrm{cM}$ (total map length $455.8 \mathrm{cM}$ ), and $Q Y$ r.nwafu- $7 B L$ spanned an interval from 341.4 to $344.2 \mathrm{cM}$ (Fig. 3D).

Development and validation of user-friendly markers for $Q Y r . n w a f u-7 B L$. To determine the robustness of identified markers for QYr.nwafu-7BL, the flanking markers were converted into KASP markers and assayed in both the RIL population and the diversity panel (Supplementary Table S4; Fig. $2 \mathrm{~A})$. The genotyping assays generated two groups for each marker, enabled by biallelic scoring of each SNP (Fig. 4A). Single-marker analyses showed that $A X-109317388$ and $A X$ 108987034 were significantly associated with the DS scores of the wheat panel $(P<0.001)$ (Fig. 4B). Several CIMMYT wheat lines known to possess QTL on 7BL carried T-A haplotypes at both SNP loci. In fact, the T-A haplotype at both loci in wheat accessions was associated with resistance, suggesting that selection on the basis of both markers was more accurate than when based on either marker alone. Pedigrees indicated that most of the accessions with the same haplotypes as P9936 because they were CIMMYT-derived lines (CIMMYT 1983). Thus, these KASP markers could be used for MAS in wheat breeding programs.
A

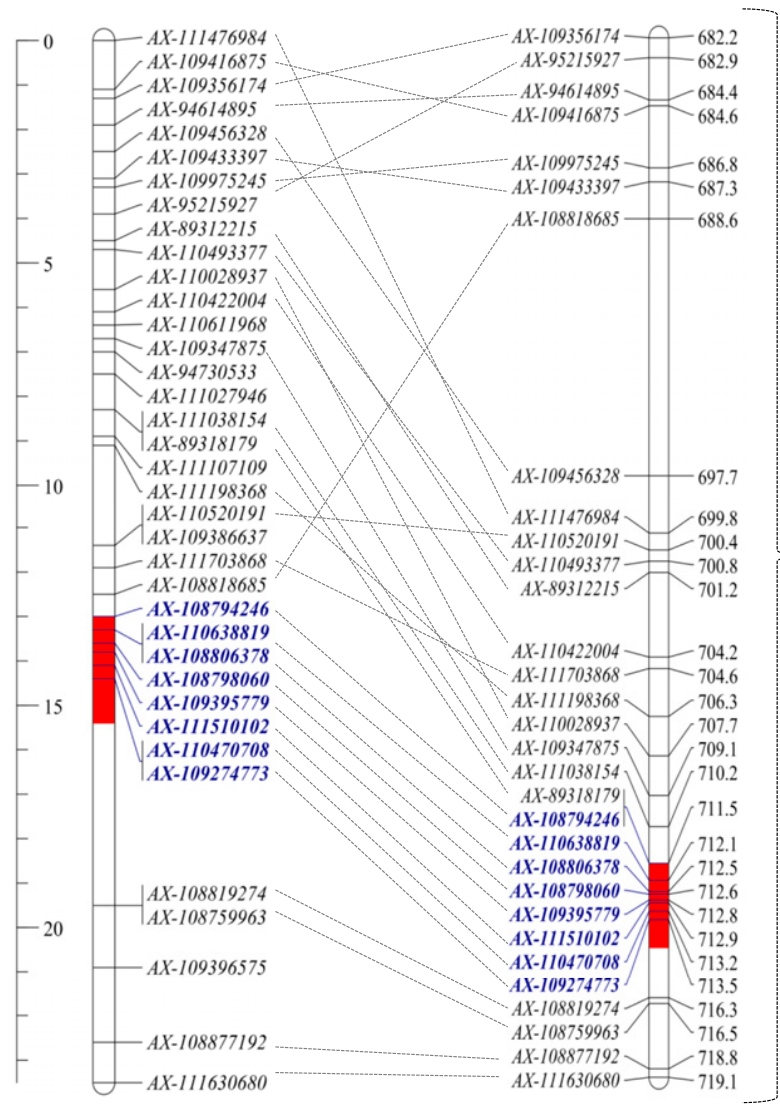

Genetic map (cM)
B

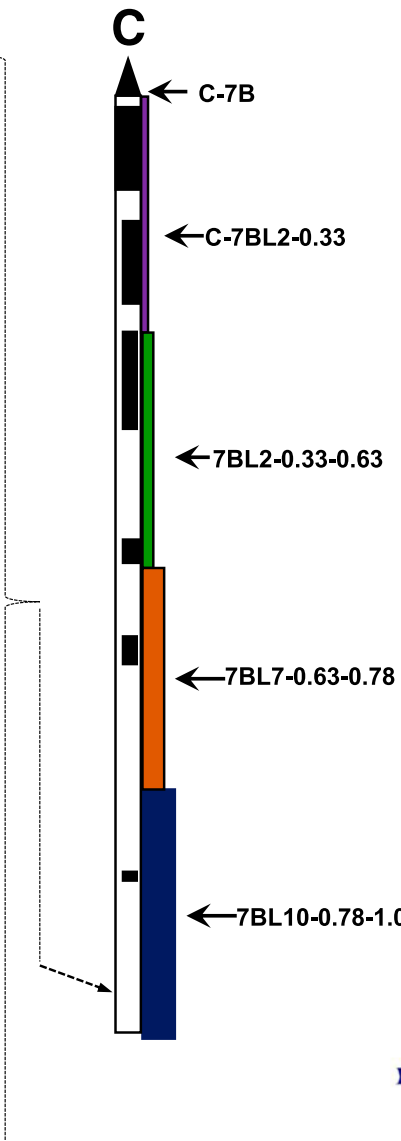

Deletion bin map

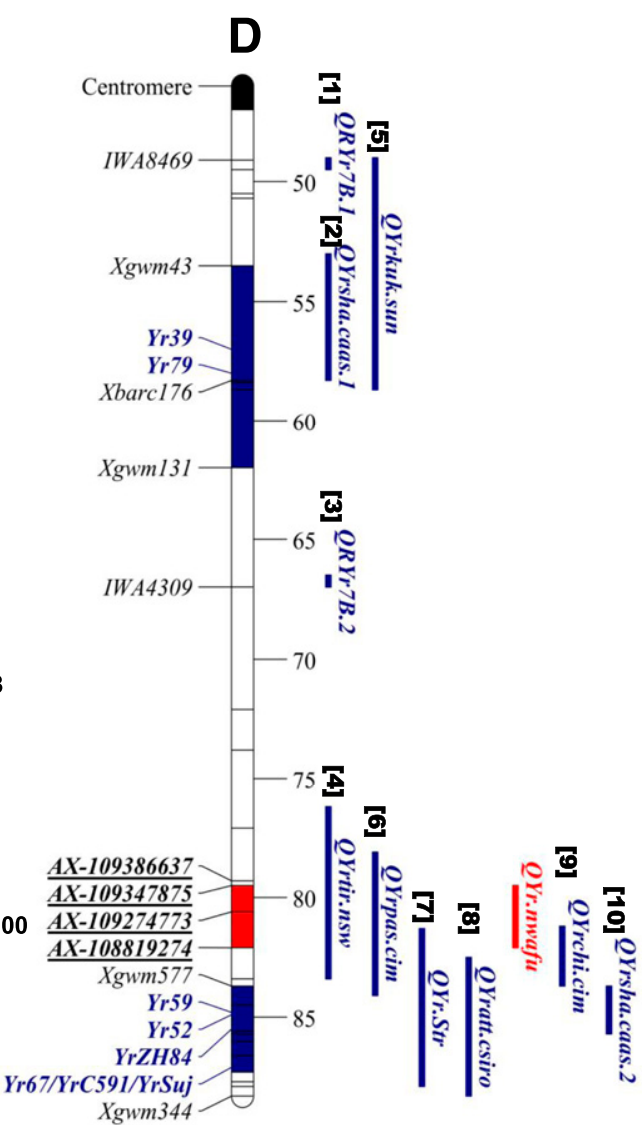

7BL consensus map (cM)

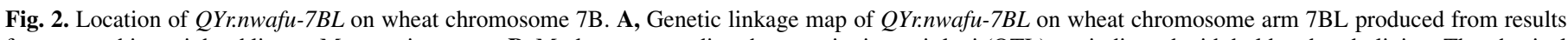

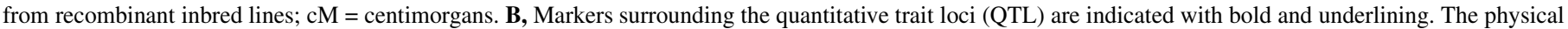

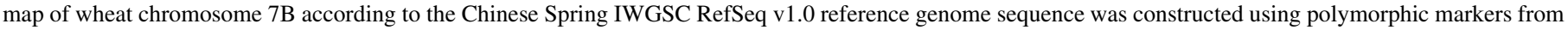

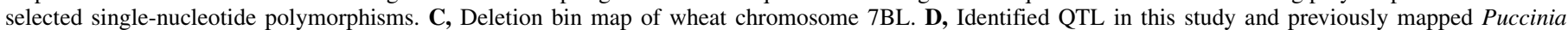

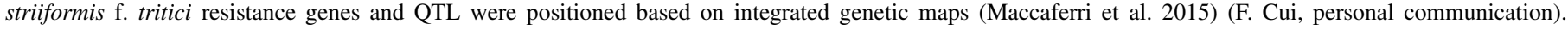

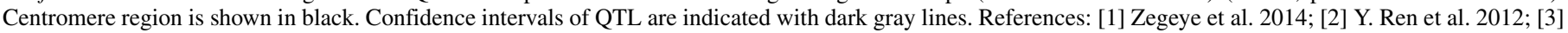

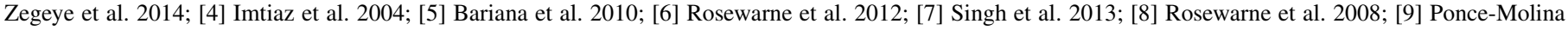
et al. 2018; [10] Y. Ren et al. 2012. 


\section{DISCUSSION}

Line P9936 has shown resistance for 10 years to stripe rust in China despite exposure to a changing and variable $P$. striiformis f. tritici population in experimental fields. The APR in P9936 was attributable to two major and two minor QTL with additive effects, and was consistently identified by both CIM and ICIM analyses across all six environments.

QYr.nwafu-7BL, located in chromosome 7BL with flanking markers $A X-108819274$ and $A X-110470708$, probably has the highest potential value for use in breeding. First, QYr.nwafu-7BL has the largest effect across environments in reducing DS, explaining up to $38.9 \%$ (ICIM) and $36 \%$ (CIM) of the phenotypic variation. Second, this gene is probably not common in current Chinese wheat cultivars and, therefore, represents a new source of resistance for local wheat breeders. Third, QYr.nwafu-7BL acted additively with the other identified QTL to enhance resistance, and gene combinations likely extend the potential durability of resistance or at least prevent extreme susceptibility in the event of a single gene failure.

Previous studies have identified several permanently and tentatively designated $Y r$ genes on chromosome 7B, including Yr39 (Lin and Chen 2007), Yr52 (R. S. Ren et al. 2012), Yr59 (Zhou et al. 2014), $\operatorname{rr67}$ (YrC591 and YrSuj) (Lan et al. 2015; Li et al. 2009; Xu et al. 2014), Yr79 (Feng et al. 2018), and YrZH84 (Li et al. 2006). In addition, there are several QTL such as QYrtir.nsw-7B in Tiritea (Imtiaz et al. 2004), QYratt.csiro-7BL in Attila (Rosewarne et al. 2008), QYrkuk.sun-7BL in Kukri (Bariana et al. 2010), QYrpas.cim$7 B L$ in Pastor (Rosewarne et al. 2012), QYrsha.caas-7BL.1 and QYrsha.caas-7BL.2 (Y. Ren et al. 2012), QYrstr-7BL in Strongfield (Singh et al. 2013), QYrchi.cim-7BL in Chilero (Ponce-Molina et al.
2018), and two QTL from a genomewide associate study (Zegeye et al. 2014). On basis of the integrated genetic map, QYr.nwafu-7BL was located at a region similar to those of QYratt.csiro-7BL, QYrchi. cim-7BL, and QYrpas.cim-7BL. Attila shares the same alleles, whereas Pastor and Chilero sources share some common alleles when assayed with KASP markers used in the present study. Rosewarne et al. (2008) found that both Pastor and Attila contain closely linked QTL for reducing stripe rust and leaf rust severity in the terminal end of chromosome 7BL. Ponce-Molina et al. (2018) also mapped QYrchi.cim-7BL in the same chromosome location as the QTL in Attila, closely linked to SSR marker Xgwm344. Pedigree analyses reveal that Attila has a close relationship to Pastor through the common parent Seri M82. Veery is one of parents of Chilero, which shares a common pedigree with Seri M82 (Kavkaz/Buho// Kalyansona/Bluebird); P9936 is related to Kalyansona/Bluebird, which is a well-known carrier of slow-rusting loci (Rosewarne et al. 2012). The QTL on 7BL in all of the above of varieties may be derived from this source. However, further studies are required to dissect the chromosomal region and confirm the genetic relationships among the stripe rust resistance genes or QTL on 7BL.

The second major QTL, QYr.nwafu-3BS, effective in all environments, likely corresponds to $S r 2 / Y r 30$. In addition to the mapping results, the $S r 2$ marker $c s S r 2$ was present in P9936, which also displayed the dark glumes characteristic of pseudo-black chaff associated with $\mathrm{Sr} 2$ at the late grain-filling stage. $\mathrm{Sr} 2 / \mathrm{Yr} 30$ is common in the CIMMYT wheat lines (Dedryver et al. 2009; William et al. 2006; Wu et al. 2017a; Yang et al. 2013). The other minor QTL QYr.nwafu-3DS and QYr.nwafu-3BL were environmentally dependent and explained $<10 \%$ of the phenotypic variation. These latter two QTL have limited value, if exploited individually, but potential interactive effects require further assessment. In the
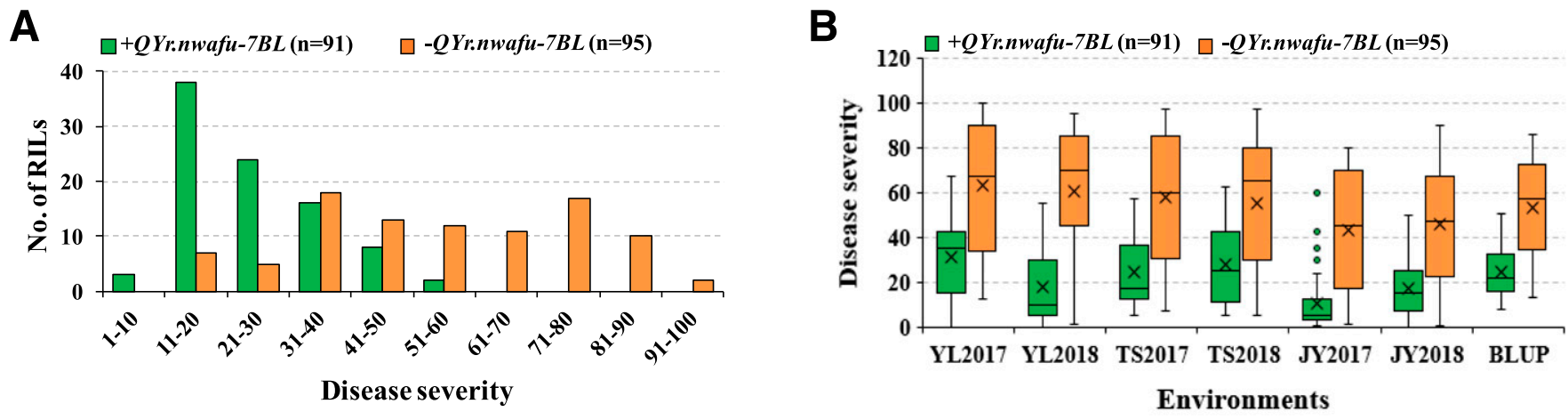

C

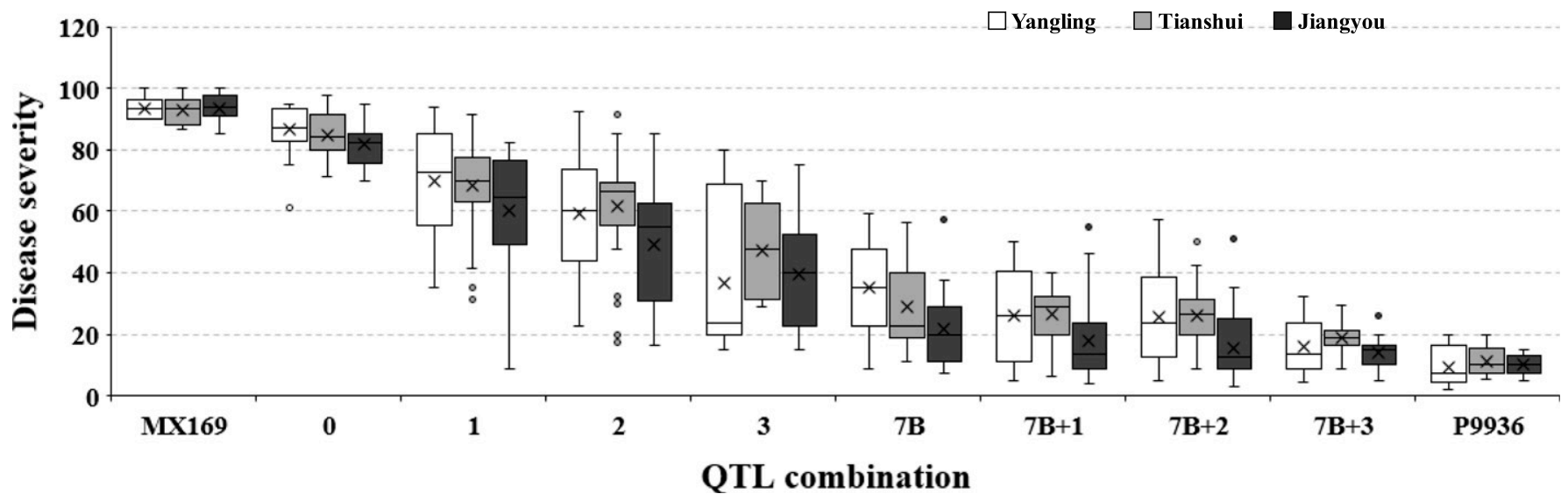

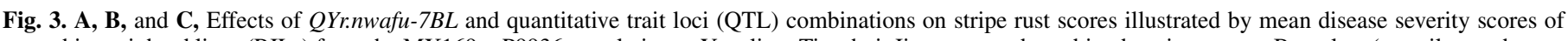

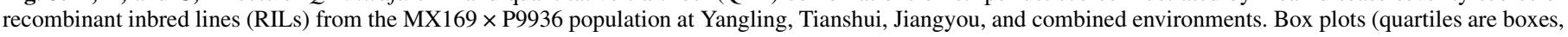

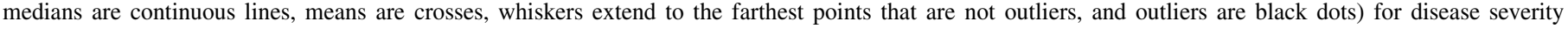
associated with the identified QTL and their combination. 
present study, these QTL enhanced the level of resistance conferred by the two major QTL, because RILs combining QTL showed higher resistance than those with one QTL. Nevertheless, when all QTL were combined, only 45.3 to $69.5 \%$ of the total phenotype variation was explained.

P9936 also carried the allele of $Y r 18$ in our previous molecular detection assay (Han et al. 2012). The slow-rusting gene $\mathrm{Yr} 18$ has conferred partial, durable resistance to stripe rust for more than 50 years (Krattinger et al. 2009). The commonly used $\mathrm{Yrl} / \mathrm{L} / \mathrm{Lr} 34$ markers, including the positive alleles of markers cssfr 3 and cssfr5, were present in both MX169 (Zeng et al. 2010) and P9936 (Han et al. 2012) as well as the RIL population. If these markers directly indicated the presence of $\mathrm{Yr} 18 / \mathrm{Lr} 34$, then MX169 should not have been susceptible, and no RIL should have been fully susceptible. The first possibility is that the frequently used markers for $\operatorname{Yr} 18$ / Lr34 are not "perfect" and that multiple haplotypes are present, only some of which are associated with resistance. On the other hand, the presence of the markers and stripe rust resistance attributable to Yr18/Lr34 in MX169 has been obtained in other RIL populations involving MX169 as a parent (Yuan et al. 2018). The diagnostic marker csLV34 for $\mathrm{Yr} 18 / \mathrm{Lr} 34$ is present in many highly susceptible varieties (Wu et al. 2015; Yang et al. 2008; Zeng et al. 2010). Wu et al. (2015) provided preliminary evidence for the presence of a suppressor of $\mathrm{Yrl} 18$ but no further supporting information has emerged. To date, three $\mathrm{Yr} 18$ haplotypes were identified and named as $+L r 34 / Y r 18,-L r 34 / Y r 18$, and $Y r 18$-Jagger. Based on the haplotypes of $\mathrm{Yr} 18$, gene-specific polymerase chain reaction markers cssfr3 and cssfr5 (Lagudah et al. 2009) and KASP markers Yr18_TCCIND and Yrl8_jagge (Rasheed et al. 2016) were developed. Given that there is evidence that $\operatorname{Yr} 18$ in MX169 is suppressed, we can consider the alternate possibilities of whether Yr18 in P9936 is or is not suppressed. If P9936 does not carry a suppressor, segregation at the suppressor locus would be detected as resistance associated with another locus or chromosome. If this is true, one of the major resistance genes reported here should be the suppressor; however, this seems unlikely. If P9936 also carried the suppressor, then neither the suppressor nor $\operatorname{Yr} 18$ would be detected.

SNP markers tightly linked to $Q Y$ r.nwafu-7BL were converted to the high-throughput, cost-effective SNP genotyping format known as KASP for use by geneticists and breeders. Validation with a large number of diverse wheat varieties revealed that the markers were significantly related to stripe rust resistance but some accessions with single markers were susceptible. However, when these two markers were used together, all accessions carrying the T-A haplotype at the identified SNP loci displayed resistance, indicating that selection for the resistance QTL will be better based on the favorable haplotype rather than individual markers.

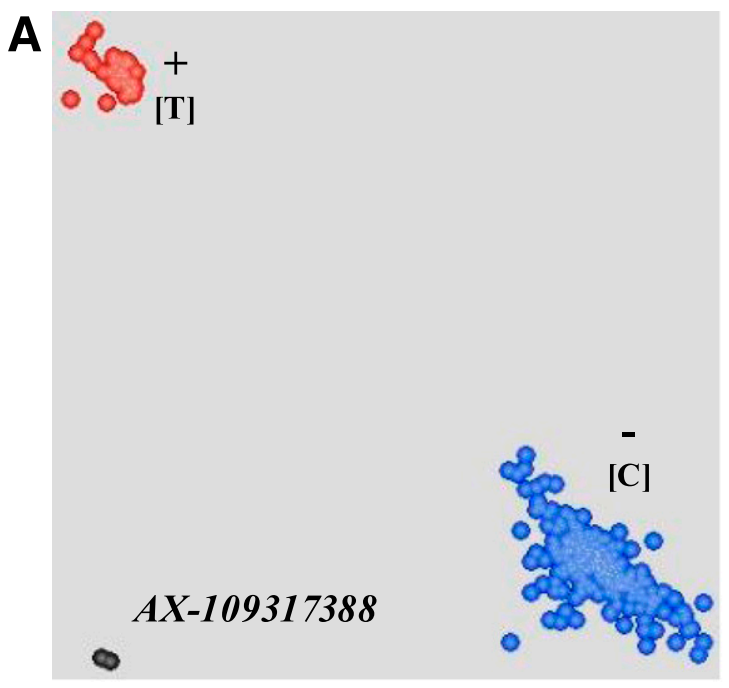

B

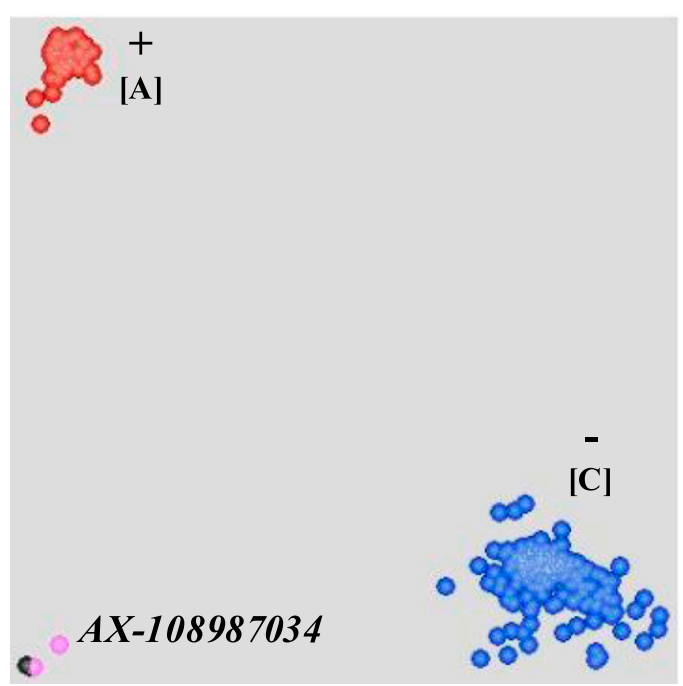

C

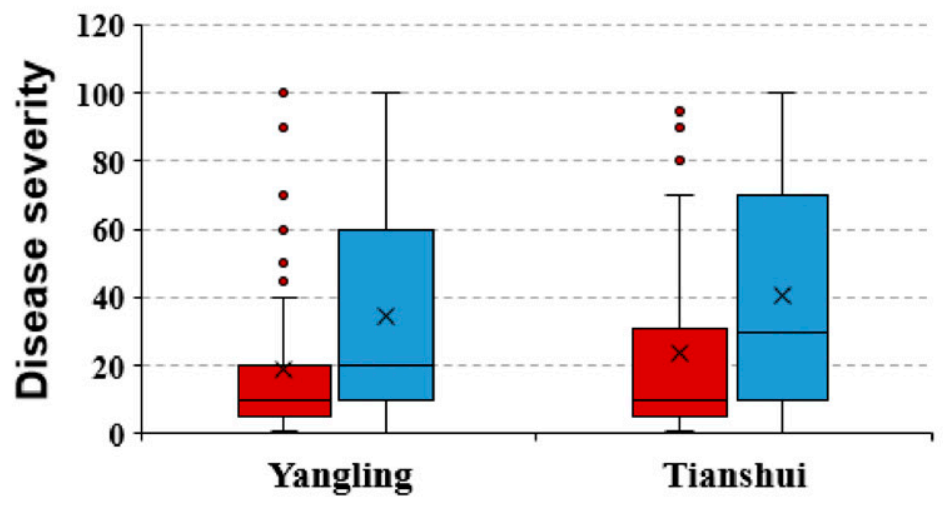

AX-109317388
D

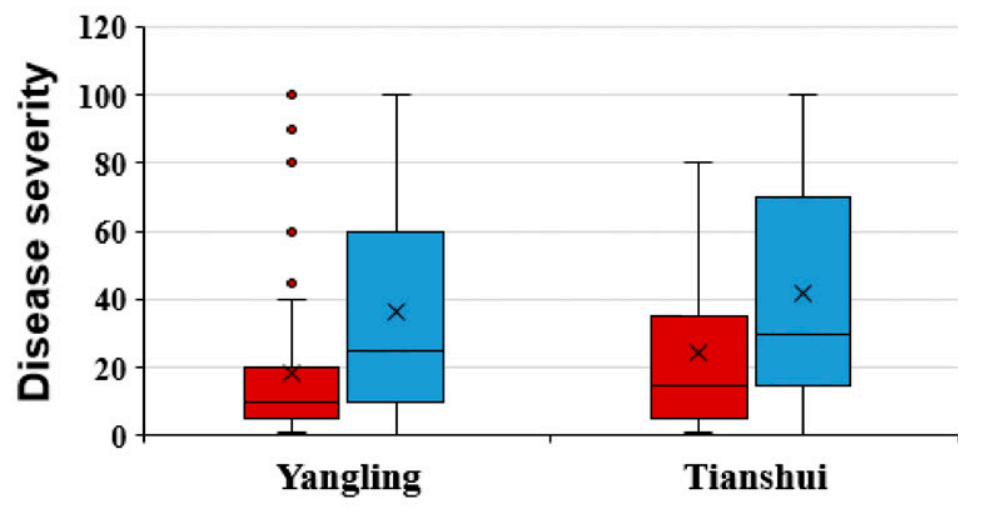

AX-108987034

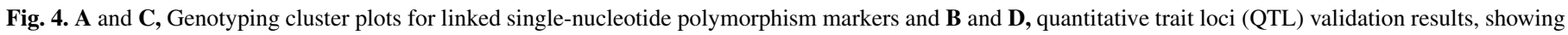

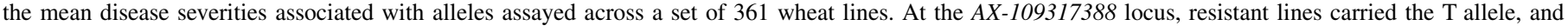
susceptible lines, the $\mathrm{C}$ allele (B); at the $A X-108987034$ locus, resistant lines carried the A allele and the susceptible lines were Cs (D). 


\section{ACKNOWLEDGMENTS}

We thank R. A. McIntosh, Plant Breeding Institute, University of Sydney, for review of this manuscript.

\section{LITERATURE CITED}

Allen, A. M., Winfield, M. O., Burridge, A. J., Downie, R. C., Benbow, H. R., Barker, G. L. A., Wilkinson, P. A., Coghill, J., Waterfall, C., Davassi, A., Scopes, G., Pirani, A., Webster, T., Brew, F., Bloor, C., Griffiths, S., Bentley, A. R., Alda, M., Jack, P., Phillips, A. L., and Edwards, K. J. 2017. Characterization of a Wheat Breeders' Array suitable for high-throughput SNP genotyping of global accessions of hexaploid bread wheat (Triticum aestivum). Plant Biotechnol. J. 15:390-401.

Bariana, H. S., Bansal, U. K., Schmidt, A., Lehmensiek, A., Kaur, J., Miah, H., Howes, N., and McIntyre, C. L. 2010. Molecular mapping of adult plant stripe rust resistance in wheat and identification of pyramided QTL genotypes. Euphytica 176:251-260.

Bates, D., Mächler, M., Bolker, B. M., and Walker, S. C. 2015. Fitting linear mixed-effects models using lme4. J. Stat. Softw. 67:1-48.

Beddow, J. M., Pardey, P. G., Chai, Y., Hurley, T. M., Kriticos, D. J., Braun, H., Park, R. F., Cuddy, W. S., and Yonow, T. 2015. Research investment implications of shifts in the global geography of wheat stripe rust. Nat. Plants 1:1-5.

Boyd, L. A. 2005. Can Robigus defeat an old enemy? - Yellow rust of wheat. J. Agric. Sci. 143:233-243.

Bulli, P., Zhang, J., Chao, S., Chen, X., and Pumphrey, M. 2016. Genetic architecture of resistance to stripe rust in a global winter wheat germplasm collection. G3: Genes Genomes Genet. 6:2237-2253.

Cavanagh, C. R., Chao, S., Wang, S., Huang, B. E., Stephen, S., Kiani, S., Forrest, K., Saintenac, C., Brown-Guedira, G. L., Akhunova, A., See, D., Bai, G., Pumphrey, M., Tomar, L., Wong, D., Kong, S., Reynolds, M., Da Silva, M. L., Bockelman, H., Talbert, L., Anderson, J. A., Dreisigacker, S., Baenziger, S., Carter, A., Korzun, V., Morrell, P. L., Dubcovsky, J., Morell, M. K., Sorrells, M. E., Hayden, M. J., and Akhunov, E. 2013. Genome-wide comparative diversity uncovers multiple targets of selection for improvement in hexaploid wheat landraces and cultivars. Proc. Natl. Acad. Sci. U.S. A. 110:8057-8062.

Chen, W. Q., Wellings, C., Chen, X. M., Kang, Z. S., and Liu, T. G. 2014. Wheat stripe (yellow) rust caused by Puccinia striformis f. sp. tritici. Mol. Plant Pathol. 15:433-446.

Chen, X. M. 2013. High-temperature adult-plant resistance, key for sustainable control of stripe rust. Am. J. Plant Sci. 4:608-627.

CIMMYT. 1983. Page 20 in: Report on Wheat Improvement. International Maize and Wheat Improvement Center, Mexico City.

Cui, F., Zhang, N., Fan, X. L., Zhang, W., Zhao, C. H., Yang, L. J., Pan, R. Q., Chen, M., Han, J., Zhao, X. Q., Ji, J., Tong, Y. P., Zhang, H. X., Jia, J. Z., Zhao, G. Y., and Li, J. M. 2017. Utilization of a wheat 660K SNP arrayderived high-density genetic map for high-resolution mapping of a major QTL for kernel number. Sci. Rep. 7: Article 3788.

Dedryver, F., Paillard, S., Mallard, S., Robert, O., Trottet, M., Negre, S., Verplancke, G., and Jahier, J. 2009. Characterization of genetic components involved in durable resistance to stripe rust in the bread wheat 'Renan'. Phytopathology 99:968-973.

Ellis, J. G., Lagudah, E. S., Spielmeyer, W., and Dodds, P. N. 2014. The past, present and future of breeding rust resistant wheat. Front. Plant Sci. 5:641.

Feng, J., Wang, M., See, D. R., Chao, S., Zheng, Y., and Chen, X. 2018. Characterization of novel gene $\mathrm{Yr} 79$ and four additional quantitative trait loci for all-stage and high-temperature adult-plant resistance to stripe rust in spring wheat PI 182103. Phytopathology 108:737-747.

Guzmán, C., Autrique, E., Mondal, S., Huerta-Espino, J., Singh, R. P., Vargas, M., Crossa, J., Amaya, A., and Peña, R. J. 2017. Genetic improvement of grain quality traits for CIMMYT semi-dwarf spring bread wheat varieties developed during 1965-2015: 50 years of breeding. Field Crops Res. 210:192-196.

Han, D. J., Zhang, P. Y., Wang, Q. L., Zeng, Q. D., Wu, J. H., Zhou, X. L., Wang, X. J., Huang, L. L., and Kang, Z. S. 2012. Identification and evaluation of resistance to stripe rust in 1980 wheat landraces and abroad germplasm. Sci Agric Sin. 45:5013-5023 [In Chinese with English summary].

Hovmøller, M. S., Walter, S., and Justesen, A. F. 2010. Escalating threat of wheat rusts. Science 329:369.

Imtiaz, M., Ahmad, M., Cromey, M. G., Griffin, W. B., and Hampton, J. G. 2004. Detection of molecular markers linked to the durable adult plant stripe rust resistance gene $Y r 18$ in bread wheat (Triticum aestivum L.). Plant Breed. 123:401-404.

Jia, J. Z., and Zhao, G. 2016. Wheat 660 SNP array developed by CAAS. https:// wheat.pw.usda.gov/ggpages/topics/Wheat660_SNP_array_developed_by_CAAS. pdf

Johnson, R. 1981. Durable resistance, definition of genetic control, and attainment in plant breeding. Phytopathology 71:567-568.
Krattinger, S. G., Lagudah, E. S., Spielmeyer, W., Singh, R. P., Huerta-Espino, J., McFadden, H., Bossolini, E., Selter, L. L., and Keller, B. 2009. A putative $\mathrm{ABC}$ transporter confers durable resistance to multiple fungal pathogens in wheat. Science 323:1360-1363.

Lagudah, E. S., Krattinger, S. G., Herrera-Foessel, S., Singh, R. P., Huerta-Espino, J., Spielmeyer, W., Brown-Guedira, G., Selter, L. L., and Keller, B. 2009. Gene-specific markers for the wheat gene Lr34/Yr18/Pm38 which confers resistance to multiple fungal pathogens. Theor. Appl. Genet. 119:889-898.

Lan, C., Zhang, Y., Herrera-Foessel, S. A., Basnet, B. R., Huerta-Espino, J., Lagudah, E. S., and Singh, R. P. 2015. Identification and characterization of pleiotropic and co-located resistance loci to leaf rust and stripe rust in bread wheat cultivar Sujata. Theor. Appl. Genet. 128:549-561.

Li, Y., Niu, Y. C., and Chen, X. M. 2009. Mapping a stripe rust resistance gene YrC591 in wheat variety C591 with SSR and AFLP markers. Theor. Appl. Genet. 118:339-346.

Li, Z. F., Zheng, T. C., He, Z. H., Li, G. Q., Xu, S. C., Li, X. P., Yang, G. Y., Singh, R. P., and Xia, X. C. 2006. Molecular tagging of stripe rust resistance gene YrZH84 in Chinese wheat line Zhou 8425B. Theor. Appl. Genet. 112: 1098-1103.

Li, Z. Q., and Zeng, S. M. 2002. Wheat Rust in China. China Agriculture Press, Beijing, China.

Lin, F., and Chen, X. M. 2007. Genetics and molecular mapping of genes for race-specific all-stage resistance and non-race-specific high-temperature adult-plant resistance to stripe rust in spring wheat cultivar Alpowa. Theor. Appl. Genet. 114:1277-1287.

Line, R. F., and Qayoum, A. 1992. Virulence, aggressiveness, evolution, and distribution of races of Puccinia striiformis (the cause of stripe rust of wheat) in North America 1968-1987. U.S. Dep. Agric. Tech. Bull. No. 1788:74.

Liu, J., Luo, W., Qin, N., Ding, P., Zhang, H., Yang, C., Mu, Y., Tang, H., Liu, Y., Li, W., Jiang, Q., Chen, G., Wei, Y., Zheng, Y., Liu, C., Lan, X., and Ma, J. 2018. A $55 \mathrm{~K}$ SNP array-based genetic map and its utilization in QTL mapping for productive tiller number in common wheat. Theor. Appl. Genet. 131:2439-2450.

Maccaferri, M., Zhang, J., Bulli, P., Abate, Z., Chao, S., Cantu, D., Bossolini, E., Chen, X., Pumphrey, M., and Dubcovsky, J. 2015. A genome-wide association study of resistance to stripe rust (Puccinia striiformis f. sp. tritici) in a worldwide collection of hexaploid spring wheat (Triticum aestivum L.). G3: Genes Genomes Genet. 5:449-465.

McDonald, B. A., and Linde, C. 2002. Pathogen population genetics, evolutionary potential, and durable resistance. Annu. Rev. Phytopathol. 40: 349-379.

McIntosh, R. A. 1992. Close genetic linkage of genes conferring adult-plant resistance to leaf rust and stripe rust in wheat. Plant Pathol. 41:523-527.

McIntosh, R. A., Dubcovsky, J., Rogers, J., Morris, C., Appels, R., and Xia, X. C. 2017. Catalogue of gene symbols for wheat: 2017 Supplement. https://shigen.nig.ac.jp/wheat/komugi/genes/macgene/supplement2017.pdf

McIntosh, R. A., Wellings, R. A., and Park, R. F. 1995. Pages 20-26 in: Wheat Rusts: An Atlas of Resistance Genes. CSIRO Publications, East Melbourne, Australia.

Meng, L., Li, H., Zhang, L., and Wang, J. 2015. QTL IciMapping: Integrated software for genetic linkage map construction and quantitative trait locus mapping in biparental populations. Crop J. 3:269-283.

Peterson, R. F., Campbell, A. B., and Hannah, A. E. 1948. A diagrammatic scale for estimating rust intensity on leaves and stems of cereals. Can. J. Res. Sect. C. 26c:496-500.

Ponce-Molina, L. J., Huerta-Espino, J., Singh, R. P., Basnet, B. R., Alvarado, G., Randhawa, M. S., Lan, C. X., Aguilar-Rincón, V. H., Lobato-Ortiz, R., and García-Zavala, J. J. 2018. Characterization of leaf rust and stripe rust resistance in spring heat 'Chilero'. Plant Dis. 102:421-427.

Ramirez-Gonzalez, R. H., Uauy, C., and Caccamo, M. 2015. PolyMarker: A fast polyploid primer design pipeline. Bioinformatics 31:2038-2039.

Rasheed, A., Hao, Y., Xia, X., Khan, A., Xu, Y., Varshney, R. K., and He, Z. 2017. Crop breeding chips and genotyping platforms: Progress, challenges, and perspectives. Mol. Plant 10:1047-1064.

Rasheed, A., Wen, W., Gao, F., Zhai, S., Jin, H., Liu, J., Guo, Q., Zhang, Y., Dreisigacker, S., Xia, X., and He, Z. 2016. Development and validation of KASP assays for genes underpinning key economic traits in bread wheat. Theor. Appl. Genet. 129:1843-1860.

Ren, R. S., Wang, M. N., Chen, X. M., and Zhang, Z. J. 2012. Characterization and molecular mapping of $Y r 52$ for high-temperature adult-plant resistance to stripe rust in spring wheat germplasm PI 183527. Theor. Appl. Genet. 125:847-857.

Ren, T., Hu, Y., Tang, Y., Li, C., Yan, B., Ren, Z., Tan, F., Tang, Z., Fu, S., and $\mathrm{Li}, \mathrm{Z}$. 2018. Utilization of a wheat 55K SNP array for mapping of major QTL for temporal expression of the tiller number. Front. Plant Sci. 9:333.

Ren, Y., He, Z., Li, J., Lillemo, M., Wu, L., Bai, B., Lu, Q., Zhu, H., Zhou, G., Du, J., Lu, Q., and Xia, X. 2012. QTL mapping of adult-plant resistance to 
stripe rust in a population derived from common wheat cultivars Naxos and Shanghai 3/Catbird. Theor. Appl. Genet. 125:1211-1221.

Rosewarne, G. M., Herrera-Foessel, S. A., Singh, R. P., Huerta-Espino, J., Lan, C. X., and He, Z. H. 2013. Quantitative trait loci of stripe rust resistance in wheat. Theor. Appl. Genet. 126:2427-2449.

Rosewarne, G. M., Singh, R. P., Huerta-Espino, J., Herrera-Foessel, S. A., Forrest, K. L., Hayden, M. J., and Rebetzke, G. J. 2012. Analysis of leaf and stripe rust severities reveals pathotype changes and multiple minor QTLs associated with resistance in an Avocet $\times$ Pastor wheat population. Theor. Appl. Genet. 124:1283-1294.

Rosewarne, G. M., Singh, R. P., Huerta-Espino, J., and Rebetzke, G. J. 2008. Quantitative trait loci for slow-rusting resistance in wheat to leaf rust and stripe rust identified with multi-environment analysis. Theor. Appl. Genet. 116:1027-1034.

Singh, A., Pandey, M. P., Singh, A. K., Knox, R. E., Ammar, K., Clarke, J. M., Clarke, F. R., Singh, R. P., Pozniak, C. J., DePauw, R. M., McCallum, B. D., Cuthbert, R. D., Randhawa, H. S., and Fetch, T. G. 2013. Identification and mapping of leaf, stem and stripe rust resistance quantitative trait loci and their interactions in durum wheat. Mol. Breed. 31:405-418.

Voorrips, R. E. 2002. MapChart: Software for the graphical presentation of linkage maps and QTLs. J. Hered. 93:77-78.

Wang, J. K. 2009. Inclusive composite interval mapping of quantitative trait genes. Acta Agron. Sin. 35:239-245.

Wang, M., Wang, S., Liang, Z., Shi, W., Gao, C., and Xia, G. 2018. From genetic stock to genome editing: Gene exploitation in wheat. Trends Biotechnol. 36:160-172.

Wang, M., Wang, S., and Xia, G. 2015. From genome to gene: A new epoch for wheat research? Trends Plant Sci. 20:380-387.

Wang, S., Wong, D., Forrest, K., Allen, A., Chao, S., Huang, B. E., Maccaferri, M., Salvi, S., Milner, S. G., Cattivelli, L., Mastrangelo, A. M., Whan, A., Stephen, S., Barker, G., Wieseke, R., Plieske, J., Lillemo, M., Mather, D., Appels, R., Dolferus, R., Brown-Guedira, G., Korol, A., Akhunova, A. R., Feuillet, C., Salse, J., Morgante, M., Pozniak, C., Luo, M., Dvorak, J., Morell, M., Dubcovsky, J., Ganal, M., Tuberosa, R., Lawley, C., Mikoulitch, I., Cavanagh, C., Edwards, K. J., Hayden, M., and Akhunov, E. 2014. Characterization of polyploid wheat genomic diversity using a highdensity 90000 single nucleotide polymorphism array. Plant Biotechnol. J. 12:787-796.

Weining, S., Ko, L., and Henry, R. J. 1994. Polymorphisms in the $\alpha$-amyl gene of wild and cultivated barley revealed by the polymerase chain reaction. Theor. Appl. Genet. 89:509-513.

Wiesner-Hanks, T., and Nelson, R. 2016. Multiple disease resistance in plants. Annu. Rev. Phytopathol. 54:229-252.

William, H. M., Singh, R. P., Huerta-Espino, J., Palacios, G., and Suenaga, K. 2006. Characterization of genetic loci conferring adult plant resistance to leaf rust and stripe rust in spring wheat. Genome 49:977-990.

Wu, J., Huang, S., Zeng, Q., Liu, S., Wang, Q., Mu, J., Yu, S., Han, D., and Kang, Z. 2018a. Comparative genome-wide mapping versus extreme poolgenotyping and development of diagnostic SNP markers linked to QTL for adult plant resistance to stripe rust in common wheat. Theor. Appl. Genet. 131:1777-1792.

Wu, J., Wang, Q., Chen, X., Liu, S., Li, H., Zeng, Q., Mu, J., Dai, M., Han, D., and Kang, Z. 2017a. Development and validation of KASP-SNP markers for QTL underlying resistance to stripe rust in common wheat cultivar P10057. Plant Dis. 101:2079-2087.

Wu, J., Wang, Q., Liu, S., Huang, S., Mu, J., Zeng, Q., Huang, L., Han, D., and Kang, Z. 2017b. Saturation mapping of a major effect QTL for stripe rust resistance on wheat chromosome 2B in cultivar Napo 63 using SNP genotyping arrays. Front. Plant Sci. 8:653.

Wu, J., Wang, Q., Xu, L., Chen, X., Li, B., Mu, J., Zeng, Q., Huang, L., Han, D., and Kang, Z. 2018b. Combining single nucleotide polymorphism genotyping array with bulked segregant analysis to map a gene controlling adult plant resistance to stripe rust in wheat Line 03031-1-5 H62. Phytopathology 108:103-113.

Wu, J., Zeng, Q., Wang, Q., Liu, S., Yu, S., Mu, J., Huang, S., Sela, H., Distelfeld, A., Huang, L., Han, D., and Kang, Z. 2018c. SNP-based pool genotyping and haplotype analysis accelerate fine-mapping of the wheat genomic region containing stripe rust resistance gene Yr26. Theor. Appl. Genet. 131:1481-1496.

Wu, J. H., Wang, Q. L., Chen, X. M., Wang, M. J., Mu, J. M., Lv, X. N., Huang, L. L., Han, D. J., and Kang, Z. S. 2016. Stripe rust resistance in wheat breeding lines developed for central Shaanxi, an overwintering region for Puccinia striiformis f. sp. tritici in China. Can. J. Plant Pathol. 38: 317-324.

Wu, L., Xia, X., Rosewarne, G. M., Zhu, H., Li, S., Zhang, Z., and He, Z. 2015. Stripe rust resistance gene $\operatorname{Yr} 18$ and its suppressor gene in Chinese wheat landraces. Plant Breed. 134:634-640.

Xu, H., Zhang, J., Zhang, P., Qie, Y., Niu, Y., Li, H., Ma, P., Xu, Y., and An, D. 2014. Development and validation of molecular markers closely linked to the wheat stripe rust resistance gene $\operatorname{YrC591}$ for marker-assisted selection. Euphytica 198:317-323.

Yang, E. N., Rosewarne, G. M., Herrera-Foessel, S. A., Huerta-Espino, J., Tang, Z. X., Sun, C. F., Ren, Z. L., and Singh, R. P. 2013. QTL analysis of the spring wheat "Chapio" identifies stable stripe rust resistance despite inter-continental genotype $\times$ environment interactions. Theor. Appl. Genet. 126:1721-1732.

Yang, W. X., Ping, Y. F., Dan, L., Hu, H. Z., Wu, S. X., and Xia, X. C. 2008. Molecular characterization of slow-rusting genes Lr34/Yr18 in Chinese wheat cultivars. Acta Agron. Sin. 34:1109-1113 [In Chinese with English summary].

Yuan, F., Zeng, Q., Wu, J., Wang, Q., Yang, Z., Liang, B., Kang, Z., Chen, X., and Han, D. 2018. QTL mapping and validation of adult plant resistance to stripe rust in Chinese wheat landrace Humai 15. Front. Plant Sci. 9:968.

Zegeye, H., Rasheed, A., Makdis, F., Badebo, A., and Ogbonnaya, F. C. 2014. Genome-wide association mapping for seedling and adult plant resistance to stripe rust in synthetic hexaploid wheat. PLoS One 9:e105593.

Zeng, Q., Wu, J., Wang, Q., Han, D., and Kang, Z. 2010. Application of durable resistance gene $\operatorname{Yr} 18$ to stripe rust in Chinese wheat breeding. J. Triticeae Crops 32:13-17 [In Chinese with English summary].

Zeng, Q.-D., Han, D.-J., Wang, Q.-L., Yuan, F.-P., Wu, J.-H., Zhang, L., Wang, X.-J., Huang, L.-L., Chen, X.-M., and Kang, Z.-S. 2014. Stripe rust resistance and genes in Chinese wheat cultivars and breeding lines. Euphytica 196:271-284.

Zeng, Q. D., Shen, C., Yuan, F. P., Wang, Q. L., Wu, J. H., Xue, W. B., Zhan, G. M., Yao, S., Chen, W., Huang, L. L., Han, D. J., and Kang, Z. S. 2015. The resistance evaluation of the $Y r$ genes to the main prevalent pathotypes of Puccinia striiformis f. sp. tritici in China. Acta Phytopathol. Sin. 45: 641-650 [In Chinese with English summary].

Zhou, X., Zhan, G., Huang, L., Han, D., and Kang, Z. 2015. Evaluation of resistance to stripe rust in eighty abroad spring wheat germplasms. Sci. Agric. Sin. 8:1518-1526 [In Chinese with English summary].

Zhou, X. L., Wang, M. N., Chen, X. M., Lu, Y., Kang, Z. S., and Jing, J. X. 2014. Identification of Yr59 conferring high-temperature adult-plant resistance to stripe rust in wheat germplasm PI 178759. Theor. Appl. Genet. 127:935-945. 